\title{
Low vitamin B-1 2 status in confirmed Alzheimer's disease as revealed by serum holotranscobalamin
}

\author{
H Refsum, A D Smith
}

J Neurol Neurosurg Psychiatry 2003;74:959-961

Objective: To examine the possible association of holotranscobalamin, the active fraction of serum cobalamin, with Alzheimer's disease.

Methods: 51 patients with pathologically confirmed Alzheimer's disease and 65 cognitively screened elderly controls were studied. Serum holotranscobalamin was measured by a new solid phase radioimmunoassay.

Results: Geometric mean levels showed no significant case-control differences for serum total cobalamin, but lower levels of holotranscobalamin in Alzheimer's disease $(41.1 \mathrm{pmol} / \mathrm{l})$ than in controls $(57.1 \mathrm{pmol} / \mathrm{l})(\mathrm{p}<0.001)$. The odds ratio of Alzheimer's disease was significant for low holotranscobalamin but not for low total cobalamin. Conclusions: Disturbed cobalamin status is common in Alzheimer's disease and accordingly measurement of holotranscobalamin should be considered in the assessment of cognitively impaired patients.

$\mathrm{T}$ en to fifteen per cent of elderly people have an undiagnosed vitamin B-12 (cobalamin) deficiency. ${ }^{1}$ Haematological signs and symptoms are, however, often not present. This deficiency is usually explained by cobalamin malabsorption in pernicious anaemia, or a failure to absorb protein bound cobalamin. ${ }^{1}$ Several studies have shown that low cobalamin status or a raised total homocysteine-a common finding in cobalamin deficiency-is associated with an increased risk of Alzheimer's disease. ${ }^{2}$ Earlier we showed that low normal cobalamin and raised total homocysteine were risk factors for pathologically confirmed Alzheimer's disease, and that a raised total homocysteine was associated with a more rapid disease progression in Alzheimer's disease. ${ }^{3}$ A recent large prospective study has shown an association of raised total homocysteine with incident Alzheimer's disease. ${ }^{4}$ Low cobalamin levels are one of the determinants of raised total homocysteine. A problem with conventional serum cobalamin measurement is that it lacks specificity and sensitivity. About $80 \%$ of total cobalamin in serum is bound to haptocorrin and is not available to the cells. The metabolically active fraction of plasma cobalamins resides in holotranscobalamin (holoTC). A decreased concentration of holoTC may thus be the earliest and the most sensitive marker of tissue cobalamin deficiency. ${ }^{5}$ Here we report our findings on holoTC and total cobalamin levels in confirmed Alzheimer's disease.

\section{METHODS}

The study population has been described previously. ${ }^{3}$ From this cohort, we selected 51 cases of histopathologically confirmed Alzheimer's disease and 65 cognitively screened controls where serum (non-fasting) was still available. Serum holoTC was directly determined, blind to diagnoses, by Dr L Örning (Axis-Shield Ltd, Oslo), using a novel solid phase radioimmunoassay. ${ }^{6}$ Serum total homocysteine was determined by high performance liquid chromatography ${ }^{7}$ and methylmalonic acid was measured by gas chromatography/ mass spectrometry. ${ }^{8}$

\section{Data analysis}

All results are expressed as mean with 95\% confidence intervals (CI), after adjustment for age and sex. Skewed variables were log transformed before analyses. Logistic regression analysis, adjusted for age and sex, was used to estimate the odds ratios of Alzheimer's disease. Low vitamin levels or high total homocysteine and methylmalonic acid levels were defined as those below about the 20th centile or above about the 80th centile, respectively, in the controls. Linear regression analyses, adjusted for age and sex, were used to examine the relation between the vitamin variables (log transformed) and Alzheimer's disease in the total group, and cognitive test scores in the control population.

\section{RESULTS}

Patient characteristics are shown in table 1. The patient group was about five years older than the control group, and the proportion of women was slightly lower. To control for these differences, we always adjusted for age and sex. The cognitive test scores and prevalence of ApoE $\epsilon 4$ were, as expected, much lower and much higher, respectively, in the patients than in the controls. Geometric mean levels showed no significant case-control differences for serum total cobalamin, but significant differences were observed for holoTC, total homocysteine, and folate, and less so for methylmalonic acid (table 1).

Table 2 shows the risk associations of the vitamin related variables with confirmed Alzheimer's disease. While low total cobalamin was not significantly associated with Alzheimer's disease, low holoTC and high methylmalonic acid were associated. Low folate and raised total homocysteine concentrations were also significantly associated with Alzheimer's disease. Including ApoE $\epsilon 4$, smoking status, and creatinine in the model did not change the overall results (table 2 ). In a conditional logistic regression model including age, sex, and all five vitamin related variables, only raised total homocysteine and low folate remained significantly associated with Alzheimer's disease (data not shown).

Splitting the dataset in two according to the median total homocysteine level showed that low holoTC was associated with Alzheimer's disease at high total homocysteine concentrations (odds ratio $=9.45(95 \% \mathrm{CI}, 2.31$ to 38.7$)$ ), but not at all at low total homocysteine concentrations (odds ratio $=0.91(0.15$ to 5.31$)$ ). In contrast, holoTC was not significantly associated with Alzheimer's disease at either high or low folate concentrations. Spearman correlations and linear regression analyses (adjusted for age, sex, and apoE) confirmed that holoTC was associated with Alzheimer's disease only at high total homocysteine concentrations (data not shown). Low folate levels also showed a much stronger association at high total homocysteine concentrations (data not shown). 
Table 1 Characteristics of the study population

\begin{tabular}{|c|c|c|c|}
\hline Variable & Controls & Cases & p Value* \\
\hline Age (years) & 70.5 (68.4 to 72.7 ) & 75.2 (72.8 to 77.7 ) & 0.005 \\
\hline Female (\%) & 67.8 & 56.7 & 0.232 \\
\hline Smokers (\%) & 14.5 & 16.7 & 0.758 \\
\hline MMSE score & $28.9(27.5$ to 30.3$)$ & 11.4 (9.8 to 13.0 ) & $<0.001$ \\
\hline CAMCOG score & 100.4 (95.6 to 105.2$)$ & $39.3(33.9$ to 44.8$)$ & $<0.001$ \\
\hline ApoE $\epsilon 4$ polymorphism (\%) & 19.5 & 73.2 & $<0.001$ \\
\hline Serum cobalamin $(\mathrm{pmol} / \mathrm{I}) \dagger$ & 302 (269 to 340 ) & 261 (228 to 298) & 0.107 \\
\hline Serum holoTC (pmol/l)† & 57.1 (51.1 to 64.1$)$ & 41.1 (36.1 to 46.8$)$ & $<0.001$ \\
\hline Serum MMA ( $\mu \mathrm{mol} / \mathrm{l}) \dagger$ & $0.23(0.20$ to 0.26$)$ & 0.28 (0.25 to 0.32$)$ & 0.027 \\
\hline Serum tHcy $(\mu \mathrm{mol} / \mathrm{l}) \dagger$ & 12.2 (11.4 to 13.1$)$ & $15.0(13.9$ to 16.3$)$ & $<0.001$ \\
\hline Serum folate $(\mathrm{nmol} / \mathrm{l}) \dagger$ & 21.5 (18.9 to 24.5$)$ & $15.2(13.1$ to 17.6$)$ & 0.001 \\
\hline Creatinine $(\mu \mathrm{mol} / \mathrm{l}) \dagger$ & 94 (90 to 98$)$ & $90(85$ to 94$)$ & 0.196 \\
\hline Low cobalamin (<200 pmol/I) (\%) & 19.0 & 30.7 & 0.158 \\
\hline Low holoTC (<40 pmol/l) (\%) & 21.5 & 47.1 & 0.004 \\
\hline Raised MMA ( $\geqslant 0.30 \mu \mathrm{mol} / \mathrm{I})(\%)$ & 20.3 & 43.1 & 0.012 \\
\hline Raised tHcy (>14 $\mu \mathrm{mol} / \mathrm{l})(\%)$ & 20.9 & 51.8 & $<0.001$ \\
\hline Low folate $(<15 \mathrm{nmol} / \mathrm{I})(\%)$ & 20.5 & 54.2 & $<0.001$ \\
\hline Raised creatinine (>1 $15 \mu \mathrm{mol} / \mathrm{l})(\%)$ & 17.0 & 3.8 & 0.027 \\
\hline
\end{tabular}

Data are mean $(95 \%$ confidence interval) or per cent.

*Adjusted for age and sex.

†Geometric mean.

CAMCOG, [spell out]; holoTC, holotranscobalamin; MMA, methylmalonic acid; MMSE, mini-mental state

examination; Hcy, total homocysteine.

Table 2 Odds ratio for association for Alzheimer's disease

\begin{tabular}{lll}
\hline & Model 1 & Model 2 \\
\hline Variable & OR $(95 \% \mathrm{Cl})$ & OR $(95 \% \mathrm{Cl})$ \\
Low cobalamin $(<200 \mathrm{pmol} / \mathrm{I})$ & $1.98(0.80$ to 4.91$)$ & $1.57(0.53$ to 4.70$)$ \\
Low holoTC $(<40 \mathrm{pmol} / \mathrm{l})$ & $3.40(1.45$ to 7.97$)$ & $2.82(1.02$ to 7.83$)$ \\
$\mathrm{MMA} \geqslant 0.30 \mu \mathrm{mol} / \mathrm{I}$ & $3.50(1.32$ to 9.29$)$ & $3.83(1.14$ to 12.85$)$ \\
tHcy $>14 \mu \mathrm{mol} / \mathrm{l}$ & $4.68(1.97$ to 11.11$)$ & $4.11(1.40$ to 12.11$)$ \\
Folate $<15 \mathrm{nmol} / \mathrm{I}$ & $4.96(2.11$ to 11.67$)$ & $3.95(1.46$ to 10.65$)$ \\
\hline
\end{tabular}

Model 1: adjusted for age and sex.

Model 2: adjusted for age, sex, smoking, creatinine, and the apoE $\epsilon 4$.

HoloTC, holotranscobalamin; MMA, methylmalonic acid; tHcy, total homocysteine.

In the control population, we examined the association between the vitamin related variables and the cognitive scores. After adjusting for age and sex, the CAMCOG (cognitive test from the Cambridge examination for mental disorders in the elderly) score was significantly associated with serum levels of both cobalamin and holoTC $(r=0.25, \mathrm{p}=0.04$ for both variables), whereas the mini-mental state examination (MMSE) was significantly related to holoTC $(r=0.29, \mathrm{p}=0.021)$ but not to cobalamin $(r=0.24, \mathrm{p}=0.059)$. Plasma concentrations of total homocysteine, folate, and methylmalonic acid were not significantly associated with CAMCOG or MMSE scores.

\section{DISCUSSION}

Previous reports on cobalamin in relation to Alzheimer's disease have shown inconsistent results. ${ }^{9-13}$ Some studies have indeed been negative. ${ }^{14}$ However, these studies have all been based on total cobalamin measurement, usually in small study populations. Our data may explain the inconsistencies. We found that the holoTC level was more strongly associated than total cobalamin with Alzheimer's disease and with cognitive function scores in controls. The finding that the association of holoTC with Alzheimer's disease was only present in subjects with high total homocysteine implies that its association may be caused by the effect of low tissue cobalamin on the level of total homocysteine, or by an interaction between homocysteine and cobalamin. ${ }^{15}$ Hence our data are consistent with the hypothesis that a raised total homocysteine level is associated with Alzheimer's disease. ${ }^{2}$ In relation to the association we have found between low holoTC levels and Alzheimer's disease, it will be of interest to see if polymorphisms in the holoTC gene that influence holoTC or total homocysteine levels are associated with an increased risk of Alzheimer's disease. ${ }^{16}{ }^{17}$

Whether low cobalamin status is a cause or a consequence of Alzheimer's disease cannot be determined from our results. However, it is noteworthy that there was an association between holoTC levels and cognitive test scores in the control group. A similar finding in elderly people has already been reported. ${ }^{18}$ We suggest that future studies on the potential role of total homocysteine and cobalamin status in relation to Alzheimer's disease and cognitive decline should include holoTC measurement in addition to conventional total cobalamin determinations. In patients with cognitive impairment, plasma total homocysteine and holoTC are probably better markers of cobalamin function than total cobalamin measurement.

Our findings have direct clinical relevance as they provide evidence that subjects with Alzheimer's disease often have impaired cobalamin status, something that can readily be corrected by treatment with vitamin $\mathrm{B}-12$.

\section{ACKNOWLEDGEMENTS}

We thank all members of OPTIMA for their help and Bristol-Myers Squibb, the Collisson Foundation and the Takayama Foundation for grants to support OPTIMA, and the Advanced Research Programme in Norway for support to HR, who is on leave from the Department of Pharmacology, University of Bergen, Norway. 


\section{Authors' affiliations}

H Refsum, Department of Pharmacology, University of Oxford, Oxford, UK

A D Smith, Oxford Project to Investigate Memory and Aging (OPTIMA), Department of Pharmacology, University of Oxford

Competing interests: Both authors have had costs to participate in scientific meetings reimbursed by Axis-Shield Ltd

Correspondence to: Professor A David Smith, University Department of Pharmacology, Mansfield Rd, Oxford OX1 3QT, UK; david.smith@pharmacology.oxford.ac.uk

Received 21 January 2003

In revised form 3 March 2003

Accepted 4 March 2003

\section{REFERENCES}

1 Carmel R. Cobalamin deficiency. In: Carmel R, Jacobsen DW, eds. Homocysteine in health and disease. Cambridge: Cambridge University Press, 2001:289-305.

2 Smith AD. Homocysteine, B vitamins, and cognitive deficit in the elderly. Am J Clin Nutr 2002:75:785-6.

3 Clarke $\mathbf{R}$, Smith $A D$, Jobst $K A$, et al. Folate, vitamin B12, and serum total homocysteine levels in confirmed Alzheimer disease. Arch Neurol 1998;55:1449-55.

4 Seshadri S, Beiser A, Selhub J, et al. Plasma homocysteine as a risk factor for dementia and Alzheimer's disease. N Engl J Med 2002;346:476-83.

5 Herbert V. Staging vitamin B-12 (cobalamin) status in vegetarians. Am J Clin Nutr 1994;59:1213-22S

6 Ulleland M, Eilertsen I, Quadros EV, et al. Direct assay for cobalamin bound to transcobalamin (holo-transcobalamin) in serum. Clin Chem 2002:48:526-32.
7 Fiskerstrand T, Refsum H, Kvalheim G, et al. Homocysteine and other thiols in plasma and urine: automated determination and sample stability. Clin Chem 1993;39:263-71.

8 Husek P. Simultaneous profile analysis of plasma amino and organic acids by capillary gas chromatography. J Chromatogr B Biomed Appl 1995;669:352-7

9 Renvall MJ, Spindler AA, Ramsdell JW, et al. Nutritional status of free-living Alzheimer's patients. Am J Med Sci 1989;298:20-7.

10 Kristensen MO, Gulmann NC, Christensen JEJ, et al. Serum cobalamin and methylmalonic acid in Alzheimer dementia. Acta Neurol Scand 1993:87:475-81.

11 Joosten $E$, Lesaffre $E$, Riezler $R$, et al. Is metabolic evidence for vitamin B-1 2 and folate deficiency more frequent in elderly patients with Alzheimer's disease? J Gerontol Ser A Biol Sci Med 1997;52:M76-9.

12 McCaddon A, Davies G, Hudson P, et al. Total serum homocysteine in senile dementia of Alzheimer type. Int J Geriatr Psychiatry 1998; 13:235-9

13 Wang $\mathrm{HX}$, Wahlin $\mathrm{A}$, Basun $\mathrm{H}$, et al. Vitamin B12 and folate in relation to the development of Alzheimer's disease. Neurology 2001;56:1188-94

14 Basun H, Fratiglioni L, Winblad B. Cobalamin levels are not reduced in Alzheimer's disease: results from a population-based study. J Am Geriatr Soc 1994:42: 132-6.

15 McCaddon A, Regland B, Hudson P, et al. Functional vitamin B 12 deficiency and Alzheimer disease. Neurology 2002;58:1395-9.

16 Namour F, Olivier J, Abdelmouttaleb I, et al. Transcobalamin codon 259 polymorphism in HT-29 and Caco-2 cells and in Caucasians: relation to transcobalamin and homocysteine concentration in blood. Blood 2001;97:1092-8.

17 Lievers KJ, Afman LA, Kluijtmans LA, et al. Polymorphisms in the transcobalamin gene: association with plasma homocysteine in healthy individuals and vascular disease patients. Clin Chem 2002;48: 1383-9.

18 Bjorksten KS, Dige N, Nexo E. Long-term memory correlates negatively with plasma transcobalamin in healthy elderly with normal plasma cobalamin levels. Int J Geriatr Psychiatry 2001;16:439-41.

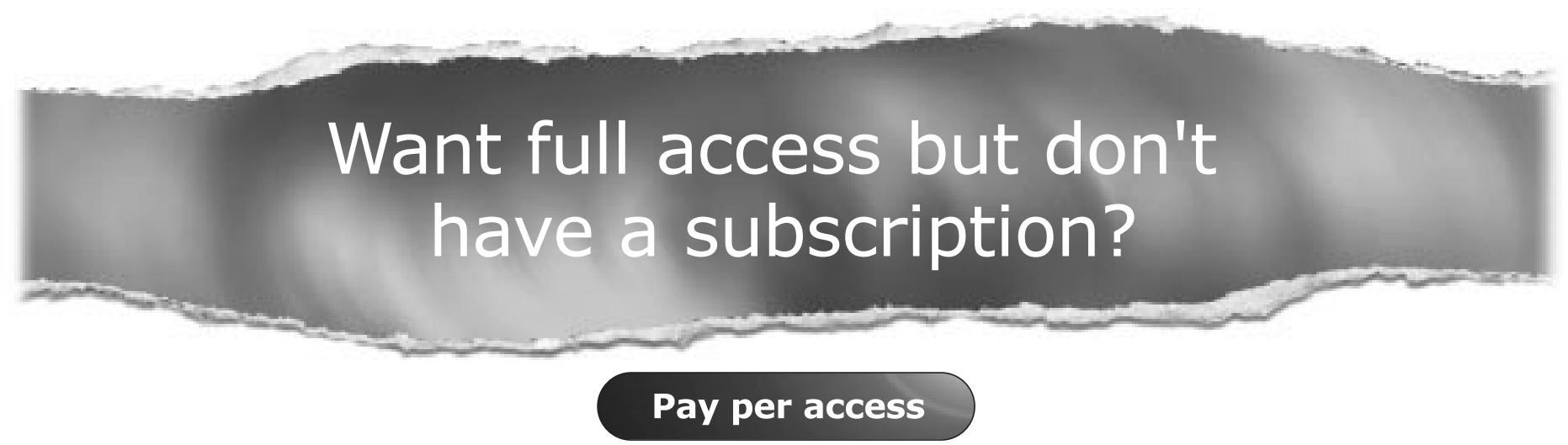

For just US $\$ 25$ you can have instant access to the whole website for 30 days. During this time you will be able to access the full text for all issues (including supplements) available. You will also be able to download and print any relevant pdf files for personal use, and take advantage of all the special features Journal of Neurology, Neurosurgery, and Psychiatry online has to offer.

\section{www.jnnp.com}

